\title{
Should recommendations for percutaneous intervention on left main coronary artery be revised?
}

\author{
Tomislav Krčmar* \\ University Hospital Centre \\ "Sestre milosrdnice", Zagreb, \\ Croatia
}

KEYWORDS: percutaneous intervention on left main coronary artery, guidelines.
CITATION: Cardiol Croat. 2018;13(1-2):43. I https://doi.org/10.15836/ccar2018.43

*ADDRESS FOR CORRESPONDENCE: Tomislav Krčmar, Klinički bolnički centar Sestre milosrdnice, Vinogradska cesta 29, HR-10000 Zagreb, Croatia. / Phone: +385-99-5200-051 / E-mail: tomislav.krcmar@gmail.com

ORCID: Tomislav Krčmar, https://orcid.org/0000-0003-4689-1673

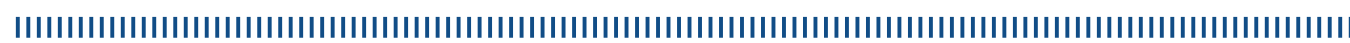

Over 40 years have gone since first percutaneous intervention on left main (LM PCI) and we still deal with many controversies. Guidelines for LM PCI have evolved through time. First "green light" for LM PCI was in American guidelines from 2009: LM PCI may be considered in patients with anatomic conditions that are associated with a low risk of PCI procedural complications and clinical conditions that predict an increased risk of adverse surgical outcomes. Last American and European guidelines from 2014 gave PCI and coronary artery bypass graft (CABG) surgery IB recommendation for treatment of low SYNTAX patients mostly because of data driven from sub-analysis of SYNTAX trial. Two studies presented and published in late 2016 on the treatment of unprotected left main coronary came up with conflicting results. In the EXCEL trial published in the New England Journal of Medicine ${ }^{1}$, patients with low- or intermediate-SYNTAX scores treated with an everolimus-eluting metallic stent had comparable rates of death, stroke, or myocardial infarction (MI) at 3 years when compared with patients treated with CABG surgery. Investigators also saw more periprocedural MI and ST-segment elevation MI in the CABG-treated patients at 30 days. In contrast, in the NOBLE trial2 ${ }^{2}$, published in the Lancet treatment with PCI using predominantly a biolimus-eluting stent was associated with a significantly higher rate of major adverse cardiac and cerebrovascular events at 5 years when compared with CABG surgery. Individually, all-cause mortality was comparable between the two treatments, while nonprocedural MI and the need for a repeat coronary revascularization were higher among those treated with PCI. Stroke rates were higher among the CABG patients at 30 days but numerically higher among PCI patients at 5 years. Two large meta-analysis from 2017 concludes that all-cause mortality is similar from PCI or CABG treatment. When we consider all new data from 2016. and 2017, PCI with new-generation DES confers similar outcomes as CABG in terms of mortality throughout 5 years, but still it suffers from increased need for repeat revascularization after PCI and less protection for non-procedural MI In conclusion, probably is time to change the guidelines on LM treatment towards IA grade recommendation for LM PCI and CABG for low to intermediate SYNTAX patients.
RECEIVED:

February 4, 2018

ACCEPTED:

February 10, 2018

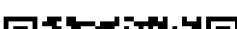

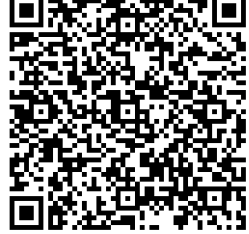

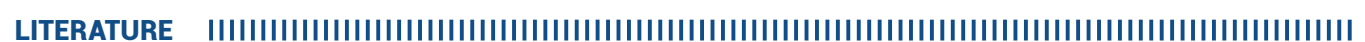

1. Stone GW, Sabik JF, Serruys PW, Simonton CA, Généreux P, Puskas J, et al; EXCEL Trial Investigators. Everolimus-Eluting Stents or Bypass Surgery for Left Main Coronary Artery Disease. N Engl J Med. 2016 Dec 8;375(23):2223-2235. https://doi.org/10.1056/NEJMoa1610227

2. Mäkikallio T, Holm NR, Lindsay M, Spence MS, Erglis A, Menown IB, et al; NOBLE study investigators. Percutaneous coronary angioplasty versus coronary artery bypass grafting in treatment of unprotected left main stenosis (NOBLE): a prospective, randomised, open-label, non-inferiority trial. Lancet. 2016 Dec 3;388(10061):2743-2752. https://doi.org/10.1016/S0140-6736(16)32052-9 